\title{
Análise da dinâmica de redes dos atos de concentração econômica em empresas da área da saúde no Brasil
}

\section{Analysis of network dynamics of Market concentration in healthcare companies in Brazil}

\author{
Luana Martins Oliveira ${ }^{\mathrm{a}}$ \\ (iD) https://orcid.org/0000-0003-4639-4546 \\ E-mail: luanalmoı9.09ळgmail.com \\ João Paulo Calembo Batista Menezes ${ }^{\text {b }}$ \\ (iD) https://orcid.org/0000-0002-4739-839X \\ E-mail: joao.calembo®ufvjm.edu.br

\section{Mirian Ribeiroc} \\ (D) https://orcid.org/0000-0002-4256-220X \\ E-mail: mirianninaœgmail.com

\section{Márcio Augusto Gonçalves ${ }^{d}$ \\ (D) https://orcid.org/0000-0003-2995-170X \\ E-mail: marcioukळyahoo.com}

\section{Marcio Coutinho de Souza ${ }^{e}$ \\ (iD) https://orcid.org/0000-0002-4238-1572 \\ E-mail: marcio.souza®ufvjm.edu.br}

aniversidade Federal de Minas Gerais. Faculdade de Ciências Econômicas/CEPEAD. Belo Horizonte, MG, Brasil.

bUniversidade Federal dos Vales do Jequitinhonha e Mucuri. Faculdade de Ciências Sociais Aplicadas e Exatas. DCCO. Teófilo Otoni, MG, Brasil.

'Universidade. Federal de Ouro Preto/ICSA. DEECO. Mariana, MG, Brasil.

¿Universidade Federal de Minas Gerais. Faculdade de Ciências Econômicas/CEPEAD. Departamento de Ciências Administrativas. Belo Horizonte, MG, Brasil.

eUniversidade Federal dos Vales do Jequitinhonha e Mucuri. Faculdade de Ciências Sociais Aplicadas e Exatas/PPGAP. Departamento de Administração. Teófilo Otoni, MG, Brasil.

\section{Correspondência}

\section{Resumo}

A promulgação da Lei $n^{0} 13.097 / 15$ estendeu a possibilidade da participação de empresas estrangeiras na área da saúde no Brasil, até então acessível a apenas alguns setores, como o da saúde suplementar. Nesse contexto, o objetivo, no presente trabalho, foi caracterizar a dinâmica das redes de operações de atos de concentração econômica em hospitais e em planos de saúde no Brasil. Para isso, foram coletados dados nos processos disponibilizados no sítio do Conselho Administrativo de Defesa Econômica (Cade), organizados a partir da estrutura societária e da origem dos investidores (estrangeira ou nacional) e analisados com a utilização de software para análise de redes. Por meio da análise dos dados, foi identificada a realização de 93 atos de concentração econômica no período de 2009 a 2017 e a participação de 12 empresas estrangeiras com origem predominante nos Estados Unidos da América. Esses atos de concentração evidenciaram a formação de uma robusta rede composta por três grupos econômicos com controle societário predominantemente estrangeiro, bem como uma latente necessidade de que sejam estabelecidas políticas para analisar os riscos e os benefícios dessa nova realidade ao mercado da saúde brasileiro. Caso contrário, colocar-se-á à sorte os potenciais reflexos no sistema de saúde brasileiro.

Palavras-chave: Saúde; Atos de Concentração; Rede. 


\section{Introdução}

The promulgation of Law No.13,097 / 15 extended the possibility of the participation of foreign companies in the health area in Brazil, until then accessible to some sectors, such as supplementary health. In this context, this paper seeks to characterize the dynamics of the networks of operations of economic concentration acts in hospitals and health plans in Brazil. For such purpose, data were collected from the processes available on the website of the Administrative Council for Economic Defense (CADE), organized from the corporate structure, originated by investors (foreign or national) and analyzed using network analysis software. In data analysis, 93 acts of economic concentration were identified from 2009 to 2017 , the participation of 12 foreign companies with predominant origin from the United States of America. These acts of concentration evidenced the formation of a robust network composed of three economic groups with predominantly foreign corporate control and a latent need to establish policies to analyze the risks and benefits of this new reality to the Brazilian health market. In another scenario, potential reflexes in the Brazilian health system will be fortunate.

Keywords: Health; Concentration Acts; Network.
No sistema de saúde brasileiro, o financiamento e o provimento dos bens e serviços de saúde são realizados pelos setores público e privado, o que o caracteriza como um sistema misto (Andrade et al. 2015).

Essa relação público-privado na prestação de serviços de saúde ao cidadão brasileiro está definida no artigo 197 da Constituição de 1988 (Brasil, 1988), muito embora essa mesma Constituição defina saúde como um direito público, gratuito e universal, expandindo a complexidade do sistema. Nesse contexto, dada a participação do setor privado nos serviços de saúde, ao longo dos últimos anos essa dualidade vem tornando cada vez mais conflituosa uma relação inicialmente baseada em um “direito", transmutado em um "produto". Um dos principais problemas dessa complexa organização industrial com características peculiares, em comparação com outros mercados, é a forma de financiamento.

Em linhas gerais, as políticas públicas relativas ao financiamento da saúde são estabelecidas, em alguns momentos, em benefício do setor público e, em outros, em benefício do setor privado ou, até mesmo, transvestidas de benefícios recíprocos, sob a alegação de que os serviços públicos e privados são precários (Brasil, 2014). Diante de um sistema público de saúde precarizado, que não consegue disponibilizar uma assistência integral e universal de qualidade, abre-se espaço favorável para várias possibilidades de expansão do setor privado (Zocratto, 2014). Especificamente quanto à forma de financiamento do setor da saúde, dois exemplos de políticas públicas podem ser destacados. 0 primeiro é relativo ao mercado da saúde suplementar, e o segundo ao mercado hospitalar em geral, ambos com a participação de capital estrangeiro em comum.

Logo após a estruturação do mercado de saúde suplementar, em 1998, pela Lei nº 9.656 (Brasil, 1998), passados pouco mais de 10 anos da promulgação da Constituição, a Medida Provisória ${ }^{0} 1.908$ 18/99 (Brasil, 1999) introduziu a possibilidade de participação de empresas estrangeiras nas operadoras de planos de saúde. O artigo 199 da Constituição de 1988 (Brasil, 1988) estabeleceu a necessidade de legislação específica para esse caso, o que foi, portanto, definido pela referida Medida 
Provisória e posteriormente solidificado na Medida Provisória nº 2.177-44/o1 (Brasil, 2001). A definição dessa política gerou uma anomalia no setor da saúde, já que, embora houvesse legislação específica via medida provisória, havia também vedação expressa quanto à participação de investidores estrangeiros na assistência à saúde, conforme estabelecia o artigo 23 da Lei ${ }^{\circ}$ 8.08o, de 1990 (Brasil, 1990).

Nesse contexto, como esclarecido pelo documento $\mathrm{n}^{\mathrm{0}} \mathrm{oo2}$ da Procuradoria Geral Federal, de 2008, (PGF, 2008) seria possível haver, por exemplo, um investidor estrangeiro em uma operadora de saúde suplementar, que, por sua vez, poderia possuir um hospital em sua rede própria, mas não poderia haver hospitais que tivessem a participação direta de investimento estrangeiro. Esse contrassenso foi mantido até 2015, quando o referido artigo 23 da Lei $\mathrm{n}^{0} 8.080$ foi alterado pela Lei $\mathrm{n}^{\circ} 13.097$ (Brasil, 2015), permitindo a atuação irrestrita de investidores estrangeiros no mercado da saúde brasileiro.

Esse cenário de abertura do mercado a investidores estrangeiros e o crescimento do interesse no mercado da saúde em escala global impulsionaram operações de atos de concentração econômica em planos de saúde e em hospitais do país, como evidenciado por Andrade et al. (2015) e Menezes (2019). Por meio dos atos de concentração econômica, empresas privadas da área da saúde podem se organizar em rede no intuito de explorar oportunidades de mercado, reduzir custos, facilitar a alocação de recursos e expandir suas fronteiras de atuação. Em contrapartida, podem formar estruturas anticompetitivas que prejudicam o mercado. Diante disso, este trabalho fundamentouse na seguinte questão: quais as características da dinâmica de redes dos atos de concentração econômica realizados, no período de 2009 a 2017 , entre o setor de planos de saúde e o setor hospitalar no Brasil? Na importância de caracterizar a dinâmica das redes de operações de atos de concentração econômica em hospitais e planos de saúde no Brasil.

Para tanto, foram coletados dados de 2009 a 2017 nos processos disponibilizados no sítio do Conselho Administrativo de Defesa Econômica (Cade), organizados a partir de estrutura societária e origem dos investidores (estrangeira ou nacional) e analisados por meio de software para análise de redes, especificamente Ucinet e NetDraw.
Com base nessa análise foi possível apresentar um mapa evolutivo das operações realizadas ao longo desses anos, determinar os grupos econômicos predominantes, sua origem e as características peculiares de cada uma das transações.

\section{Material e métodos}

Trata-se de um estudo descritivo, de abordagem quantitativa, baseado em dados secundários que foram coletados no sítio do Cade, com base nos volumes de processos por ele disponibilizados. Os dados e as informações sobre os atos de concentração e as empresas envolvidas foram extraídos dos volumes dos processos que foram obtidos sistematicamente da seguinte forma: no sítio do Cade, na seção Pesquisa Processual, foram pesquisados os termos "hospital" e "saúde", no período de $1^{\circ}$ de janeiro de 2009 a 31 de dezembro de 2017 , selecionando-se os seguintes itens: processos; documentos gerados e documentos externos; se o tipo de processo foi finalístico; e ato de concentração sumário (processo de decisão simplificada) e ordinário (processo de decisão com análise pormenorizada).

Os atos de concentração sumários compreendem aqueles que apresentam menor potencial ofensivo à concorrência, dada a simplicidade das operações; por sua vez, os atos ordinários são aqueles mais ofensivos à concorrência e com maior grau de complexidade da operação (Cade, 2012). “Atos de concentração se justificam, do ponto de vista empresarial, pela perspectiva de exploração de sinergias econômicas e financeiras entre as empresas e pela expectativa de maiores excedentes para as requerentes após a operação" (Cade, 2016, p. 45).

Os dados coletados foram organizados em planilhas eletrônicas e a análise da dinâmica de redes foi realizada por meio do Software Ucinet e NetDraw.

Para a análise da Dinâmica de Redes, o banco de dados foi formado por 211 empresas e três pessoas físicas que realizaram atos de concentração econômica no Brasil, no período de 2009 a 2017 , envolvendo hospitais e/ou planos de saúde. Embora não tenha sido o escopo do presente trabalho abordar aspectos relativos à Teoria das Unidades de Decisão, proposta por Hermann e Hermann (1989), os atores foram tratados inicialmente como unidades 
operacionais, e posteriormente foram identificadas as unidades de decisão por meio dos nós, que por sua vez controlam as unidades operacionais no seu vínculo. Para a caracterização da rede foram calculados os indicadores densidade, distância média, grau de centralidade e grau de intermediação, descritos por Alejandro e Norman (2005), conforme se observa no Quadro 1.

\section{Quadro I - Indicadores para caracterização da rede}

\begin{tabular}{|c|c|}
\hline Indicador & Descrição \\
\hline Densidade & $\begin{array}{l}\text { Mostra-nos o valor, em percentagem, da Densidade da Rede, isto é, a alta ou a baixa conectividade } \\
\text { da Rede. É uma medida expressa em percentagem do quociente entre o número de relações } \\
\text { existentes com as relações possíveis. }\end{array}$ \\
\hline Distância média & É o menor número de laços necessários para conectar, direta ou indiretamente, um ator a outro na rede \\
\hline Grau de centralidade & Consiste no número de atores com os quais um ator está diretamente relacionado. \\
\hline Grau de intermediação & $\begin{array}{l}\text { Trata-se da possibilidade que um ator tem de intermediar as comunicações entre pares de nós. } \\
\text { Estes atores também são conhecidos como "atores-ponte". }\end{array}$ \\
\hline
\end{tabular}

Fonte: Alejandro e Norman (2005).

Para o cálculo dos indicadores no Ucinet e a geração dos gráficos no NetDraw, foram elaboradas matrizes relacionais binárias em planilhas eletrônicas. Exemplifica-se a construção dessas matrizes relacionais da seguinte forma: na célula $\mathrm{A}_{3}$, caso a empresa $X$ (coluna) tivesse realizado ato de concentração econômica com uma empresa Y (linha), a célula $\mathrm{A}_{3}$ era indicada com o número 1. Caso contrário, era indicado o número zero.

Ao realizar a análise da dinâmica de redes, das 211 empresas e três pessoas físicas, foi possível definir os atores principais envolvidos das operações e suas ligações, sendo que uma rede possui dois elementos principais, os "nós" (ou atores) e o vínculo. Os nós/atores, são pessoas ou grupos de pessoas que se agrupam com um objetivo comum. 0 vínculo são os laços que existem entre dois ou mais nós/autores, que são representados por linhas (Ghiradini, 2015).

Nesta pesquisa, os “nós” são as empresas e os vínculos são os atos de concentração que foram realizados entre hospitais e/ou planos de saúde, de 2009 a 2017, que tiveram as operações submetidas à avaliação do Cade. Também se caracterizam como vínculo empresas que fazem parte de um mesmo grupo econômico. Dessa forma, uma linha entre dois atores (empresas) configura que elas participaram de um mesmo ato de concentração ou fazem parte do mesmo grupo econômico. Por exemplo, na Figura 1, a Bradesco Dental realizou um ato de concentração com a Odontoprev, o que estabeleceu uma ligação entre estas empresas; já a Amil e a Amico têm uma ligação, uma vez que a Amico faz parte da Amil.

No que se refere às cores adotadas nos mapas, o preto indica as empresas "compradoras", ou seja, que adquiriram participação/carteira em outras empresas ou realizaram a solicitação da operação junto ao Cade, se configurando como a mais interessada na realização da operação; o branco indica as empresas "vendedoras", sendo aquelas que estavam vendendo participação, carteira ou emitindo debêntures, também denominadas empresas “objeto da operação”, pelo Cade, nos volumes dos processos; por fim, a cor preta, na Figura 11, indica aquelas empresas que, em sua origem, são estrangeiras. Dados os esclarecimentos iniciais, fazse a apresentação dos resultados e das discussões.

\section{Resultados e discussões}

Foram identificados 100 atos de concentração econômica em hospitais e em planos de saúde, no Brasil, no período de 2009 a 2017, dos quais foram retirados aqueles que não foram consumados pelas empresas e os que foram reprovados e não reconhecidos pelo Cade, num total de 93. Os anos em que houve maior número de operações foram 2010, 2012 e 2015. Em 2009 registrou-se o menor número de operações, apenas cinco, como se pode observar na Tabela 1. 
Tabela I - Atos de concentração econômica em hospitais e planos de saúde, por ano

\begin{tabular}{lcccc} 
Ano & $N^{0}$ de operações & Operações Ordinárias & Operações Sumárias & $N^{0}$ de Empresas \\
2009 & 5 & 2 & 3 & 11 \\
2010 & 13 & 4 & 9 & 29 \\
2011 & 12 & 0 & 12 & 31 \\
2012 & 15 & 4 & 11 & 42 \\
2013 & 10 & 3 & 7 & 20 \\
2014 & 6 & 0 & 6 & 18 \\
2015 & 13 & 1 & 12 & 37 \\
2016 & 9 & 6 & 3 & 30 \\
2017 & 10 & 3 & 7 & 32 \\
Total & 93 & 23 & 70 & 250 \\
\hline
\end{tabular}

Constatou-se que a maioria das operações realizadas de 2009 a 2017 foi aprovada pelo Cade sem restrições, $79(85 \%)$ e $14(15 \%)$ aprovadas com restrições, fator que pode ser favorável para aumentar a concentração econômica no setor da saúde. A realização de atos de concentração econômica fortalece uma empresa, uma vez que essas operações trazem vantagens, como a redução de custos, a ampliação da infraestrutura e o aumento dos lucros (Hitt; Ireland; Harrison, 2001).

Ao se verificar a origem das empresas envolvidas nas operações, a maior parte estava concentrada no estado de São Paulo, representando $49 \%$, seguido pelo Rio de Janeiro, representando $22 \%$ e Pernambuco, representando $10 \%$. A partir destas informações, pode-se perceber que as empresas que mais realizaram atos de concentração econômica no período estudado estavam localizadas na região sudeste ( $72 \%)$.

Em 2009 foram realizados cinco atos de concentração econômica, sendo quatro aprovados sem restrições pelo Cade e um aprovado com restrições. Desses, dois foram classificados como ordinários e três como sumários. Quanto ao tipo de operação, foram três aquisições de participação, uma aquisição de carteira e uma incorporação, que envolveram 11 empresas, como se observa na Figura 1.

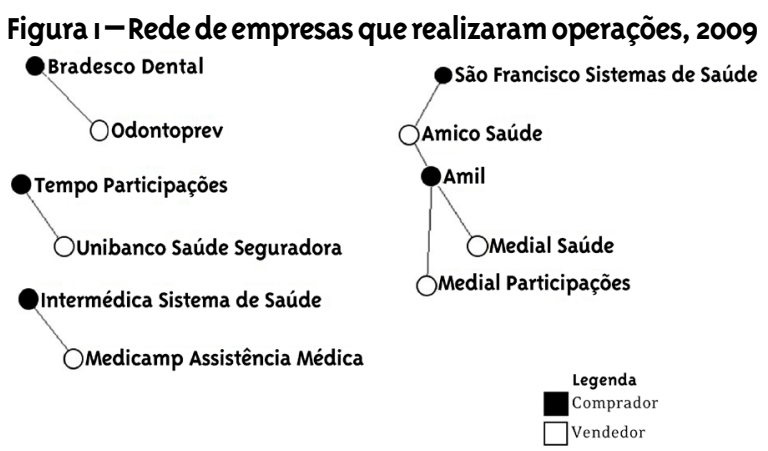

Uma operação destacou-se em 2009, quando a Amil Assistência Médica Internacional, operadora de planos de saúde de assistência médica, hospitalar e odontológica, adquiriu participação em duas empresas, a Medial Participações e a Medial Saúde, que também atuavam como operadoras de planos de saúde de assistência médica, hospitalar e odontológica.

Ao analisar o ano de 2010, percebeu-se que a quantidade de atos de concentração mais que dobrou, quando comparada com a que ocorreu no ano de 2009, saltando de cinco para 13 . Houve 10 atos aprovados sem restrições pelo Cade e três aprovados com restrições, quatro classificados como ordinários e nove como sumários, tendo todos sido aquisição de participação. Na Figura 2 é possível verificar que 29 empresas foram envolvidas. 
A FMG Empreendimentos Hospitalares esteve envolvida em cinco atos de concentração econômica com 12 empresas, no ano de 2010, conforme demonstrado na Figura 2. Também no ano de 2010 identificou-se a entrada de investimentos estrangeiros no país, quando o The Carlyle Group, uma holding administradora de ativos dos Estados Unidos com atuação global, adquiriu participação na Qualicorp Participações, que atua como operadora de planos de saúde coletivos.

A Amil Assistência Médica Internacional foi a única empresa a realizar atos de concentração nos anos de 2009 e 2010, ampliando sua atuação a cinco empresas, sendo ASL Assistência à Saúde, Ceame Centro Especializado de Atendimento Médico, Excelsior Med, Medial Saúde e Medial Participações. A partir dessas aquisições, a Amil Assistência Médica
Internacional expandiu sua participação nos estados de Pernambuco, Rio Grande do Norte e São Paulo.

Ocorreram 12 atos de concentração no ano de 2011, sendo oito aprovados sem restrições pelo Cade e quatro aprovados com restrições. Todos foram classificados como sumário quanto ao tipo de operação, sendo 10 aquisições de participação e duas cessões de direitos, que envolveram 31 empresas, como apresentado na Figura 3.

Qualicorp, Qualicorp Corretora de Seguros e Qualicorp Administradora de Benefícios faziam parte do Grupo Qualicorp, que foi adquirido, em 2010, pelo grupo The Carlyle e realizaram três operações, em 2011, que envolveram sete empresas, ampliando sua atuação nos estados do Rio de Janeiro e São Paulo, nas atividades de planos de saúde.

\section{Figura 2-Rede de empresas que realizaram operações, 2010}

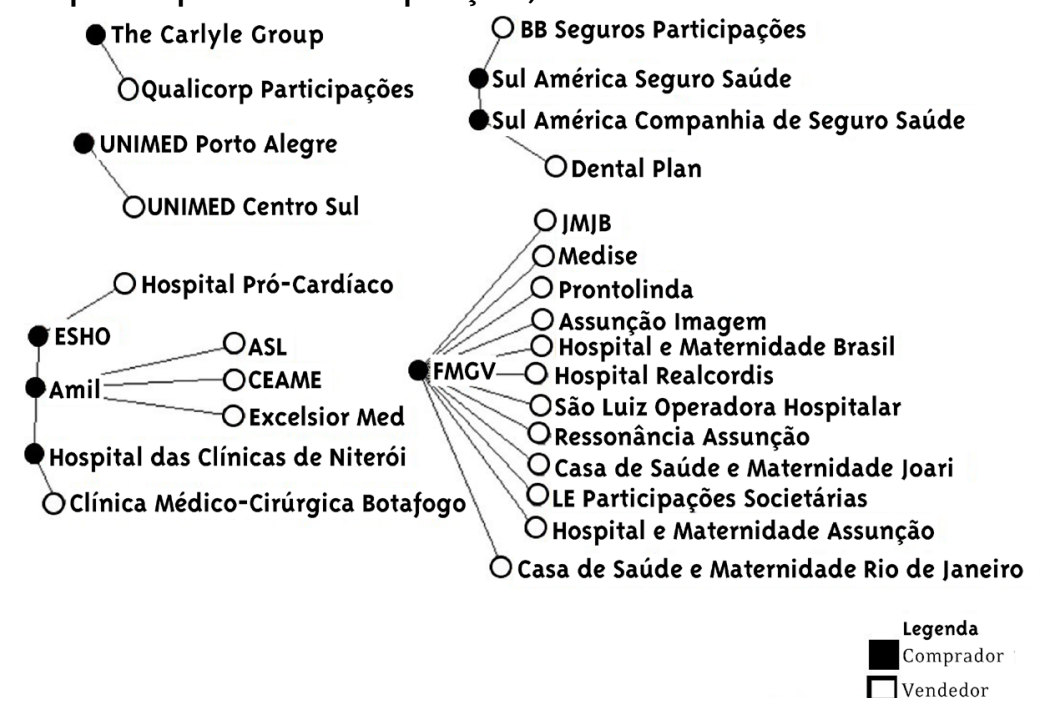

Também em 2011, a Rede D’Or São Luiz, grupo de empresas que atuam na prestação de serviços hospitalares, realizou três operações que envolveram cinco empresas, uma delas a Oncotech Oncologia, que também realizou uma operação com seis empresas de atividades hospitalares, ampliando a atuação nos estados do Rio de Janeiro e Rondônia. Duas empresas que já pertenciam ao Grupo Rede D’Or São Luiz, o Hospital Norte D’Or de Cascadura e o Centro de Tratamento em Oncologia, realizaram duas operações. 0 Hospital Norte D’Or de Cascadura adquiriu participação na Unimed-Rio Participações e Investimentos, que integra a rede de cooperativas Unimed.
Em 2012, foram registradas 15 operações que tiveram seis delas aprovadas sem restrições pelo Cade e nove aprovadas com restrições. Quanto à classificação, quatro operações foram classificadas como ordinárias e 11 como sumárias. Quanto ao tipo, foram duas aquisições de carteira, 11 aquisições de participação, uma cessão de direito e uma emissão de debêntures que, conforme se verifica na Figura 4, envolveram 42 empresas.

Os planos de saúde e hospitais, durante o período analisado, realizaram atos de concentração com empresas de várias atividades, ampliando o portfólio de serviços e produtos, o que indica uma busca por maior verticalização. 
Figura 3 - Rede de empresas que realizaram operações, 2011

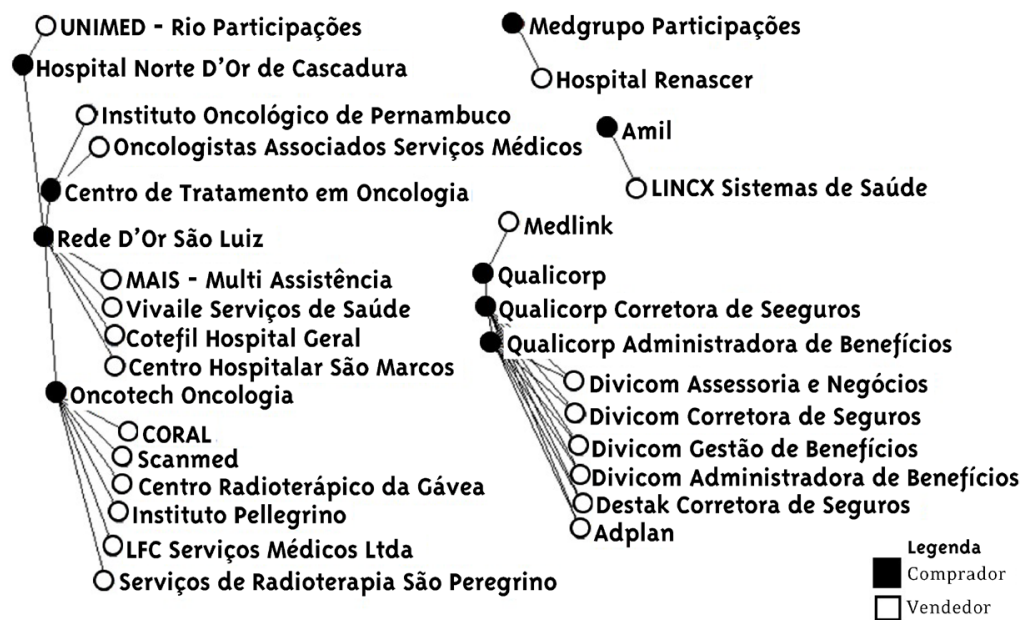

Figura 4 - Rede de empresas que realizaram operações, 2012

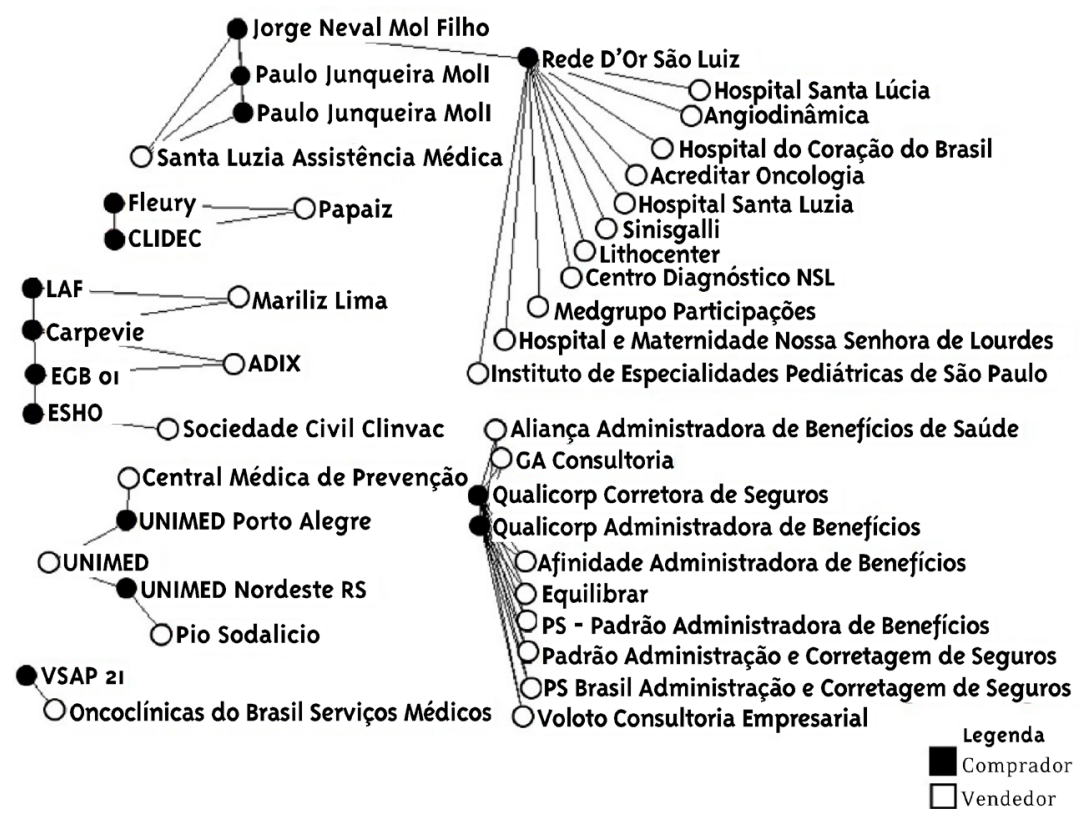

Também em 2012, as empresas controladas, até então, por Edson de Godoy Bueno, a LAF - Empresa de Serviços Hospitalares, Carpevie - Centro de Medicina Integrada, EGB o1 Empreendimentos e Participações e ESHO - Empresa de Serviços Hospitalares, realizaram três operações.

Vale destacar que, em 2012, verificaram-se investimentos estrangeiros por meio de uma operação na qual a Oncoclínicas do Brasil Serviços Médicos realizou a emissão de debêntures para o VSAP 21 Fundo de Investimento em Participações, de origem canadense, que atua na aquisição de ações, debêntures, bônus de subscrição e outros títulos em outras companhias, de acordo com o interesse de seus acionistas, e faz parte do grupo Victoria Capital Partners.

Em 2013 ocorreram 10 operações, todas aprovadas sem restrições pelo Cade, tendo três sido classificadas como ordinárias e sete como sumárias. Quanto ao tipo de operação, foram quatro aquisições de carteira, 
quatro aquisições de participação e duas associações de empresas, que envolveram 20 empresas, como demonstrado na Figura 5.

Por estar envolvida em $50 \%$ das operações, a rede de cooperativas Unimed se destacou em 2013. Ela realizou quatro aquisições de carteira e uma associação de empresas. A Unimed Odonto realizou duas operações, adquiriu a carteira de planos de assistência odontológica da Unimed Vitória e da Unimed Recife. Mesmo após a operação, a Unimed Vitória e a Unimed Recife continuaram a existir no mercado de planos de saúde, exceto em planos odontológicos.

Figura 5-Rede de empresas que realizaram operações, 2013

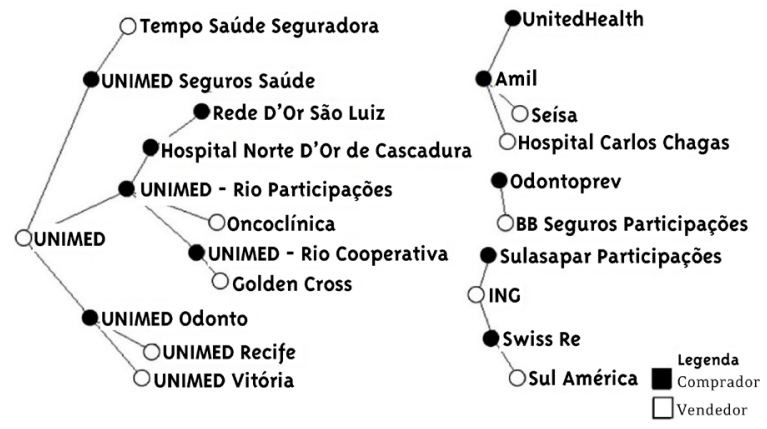

O grupo UnitedHealth, dos Estados Unidos, que atua na operação de planos de saúde e na prestação de serviços médico-hospitalares, adquiriu o controle da Amil Assistência Médica Internacional em 2012, porém, essa operação não integrou o escopo do trabalho, uma vez que não foi submetida à avaliação do Cade por não ter atingido os requisitos legais de notificação. Ainda assim, se trata de uma informação importante para o mercado da saúde no Brasil, tendo em vista que a Amil Assistência Médica Internacional era um grupo com grande atuação, com mais de 26 empresas na área da saúde e que estava diretamente ligada ao Grupo EB, que também possui várias empresas neste mercado, ambas controladas, até então, por Edson de Godoy Bueno.

Também no ano de 2013, mais uma empresa estrangeira realizou investimentos no mercado da saúde no Brasil. A Swiss Re Direct Investments Company, da Suíça, que pertencia ao grupo Swiss Re e opera em âmbito mundial como fornecedora de resseguros, seguros e de outras formas de transferência de riscos baseada em seguros, adquiriu participação na SulAmérica, que oferece diversos produtos e serviços, incluindo seguros, planos de previdência privada, gestão de ativos, planos de saúde e serviços de assistência à saúde.

No ano de 2014 houve mais reduções no número de operações, saindo de 10, em 2013, para apenas seis, em 2014. Todas as operações de 2014 foram aprovadas sem restrições pelo Cade, todas classificadas como atos sumários, sendo cinco aquisições de participação e uma incorporação, que envolveram 18 empresas, como apresentado na Figura 6.

Figura 6-Rede de empresas que realizaram operações, 2014

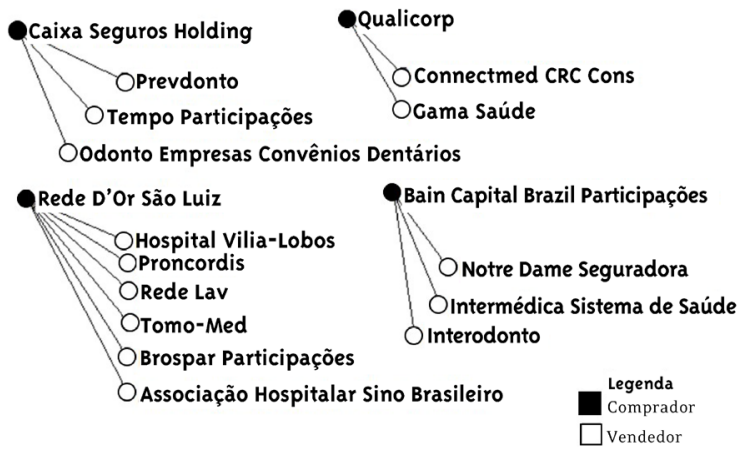

A partir dos dados da Figura 6, verifica-se que as operações realizadas no ano de 2014 se concentraram apenas em quatro empresas: Caixa Seguros Holding, Qualicorp, Rede D’Or São Luiz e Bain Capital Brasil Participações.

A empresa Bain Capital Partners, dos Estados Unidos, empresa global de investimento privado que administra diversos investimentos de capital, incluindo private equity, venture capital, investimento público, produtos de crédito e investimentos de retomo absoluto, adquiriu participação, por intermédio da Bain Capital Brasil Participações no Brasil, na Intermédica Sistema de Saúde, na Interodonto - Sistema de Saúde Odontológica e na Notre Dame Seguradora, que faziam parte do grupo Notre Dame Intermédica, operadora de assistência privada à saúde que ofertava planos médico-hospitalares no Brasil, com foco em pacotes corporativos para pequenos, médios e grandes clientes. 
Em 2015, foram realizadas 13 operações, todas aprovadas sem restrição pelo Cade, sendo uma classificada como ato ordinário e 12 como ato sumário.
Quanto ao tipo de operação, foram uma aquisição de carteira e 12 aquisições de participação, que envolveram um total de 37 empresas, como apresentado na Figura 7.

Figura 7 - Rede de empresas que realizaram operações, 2015

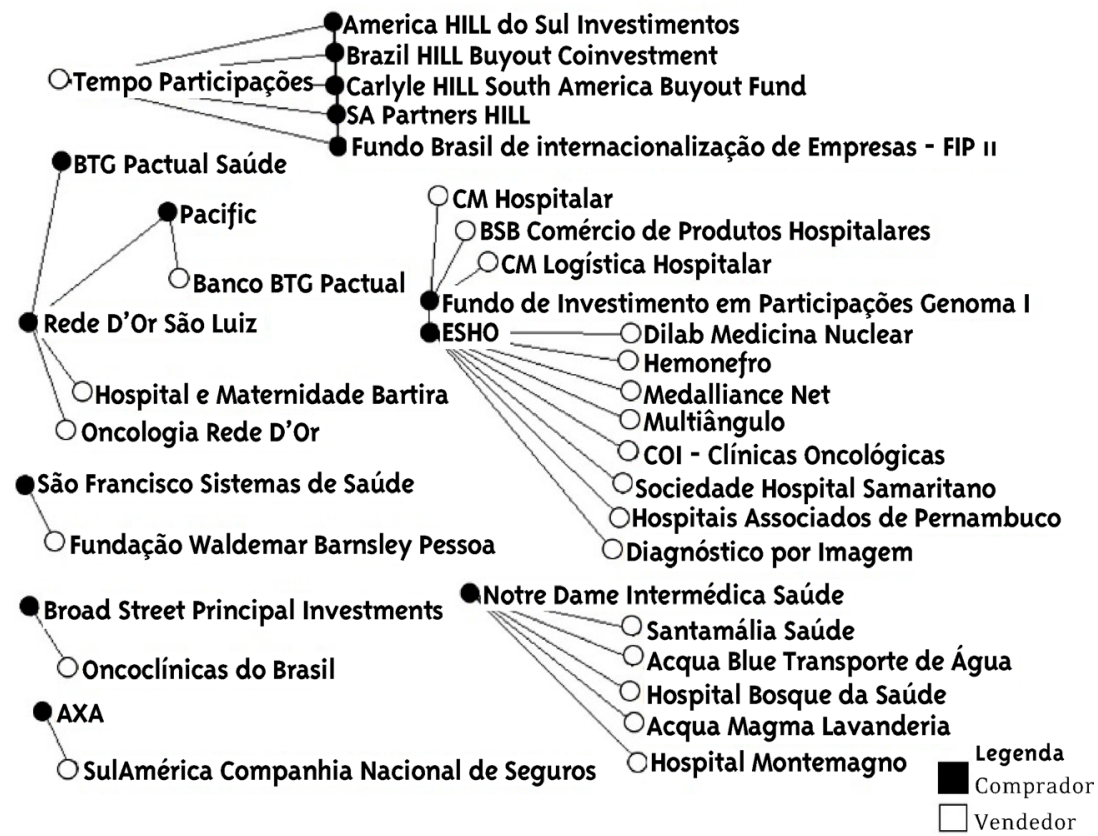

No ano de 2015 verificou-se o maior número de investimentos estrangeiros no mercado da saúde no Brasil, com a realização de quatro operações, como se descreve a seguir.

A Broad Street Principal Investments, dos Estados Unidos, uma sociedade do grupo Goldman Sachs, adquiriu participação na Oncoclínicas do Brasil Serviços Médicos, do grupo Oncoclínicas.

A partir de uma operação, a AXA Corporate Solutions Brasil e América Latina Resseguros, da França, do grupo AXA, adquiriram participação na SulAmérica Companhia Nacional de Seguros, do grupo Sulasa.

A Pacific RDSL Participações, de Singapura, gerida pelo grupo GIC Ventures, adquiriu participação na Rede D’Or São Luiz.

Na quarta operação, a Carlyle Hill South America Buyout Fund, a America Hill do Sul Investimentos, a SA Partners Hill, a Brazil Hill Buyout Coinvestment e o Fundo Brasil de Internacionalização de Empresas - FIP 11, dos Estados Unidos, fundos de investimento do grupo The Carlyle, adquiriram participação na Tempo Participações, que pertencia ao grupo Tempo.

No ano de 2016 foram realizadas nove operações, todas aprovadas sem restrições pelo Cade, além de seis atos ordinários e três sumários, sete aquisições de participação e duas cessões de direito, totalizando 30 empresas, como apresentado na Figura 8.

Verificou-se uma redução nas operações em 2016, concentradas em três grupos, sendo na Rede D’Or São Luiz, no GIF V Fundo de Investimento em Participações e no grupo de empresas controladas pela Amil, que integra o Fundo de Investimentos em Participações Genoma I, Esho - Empresa de Serviços Hospitalares, Amil Assistência Médica Internacional e Hospital Alvorada Taguatinga.

Foram identificadas 10 operações no ano de 2017, todas aprovadas sem restrições pelo Cade, tendo três atos sido classificados como ordinários e sete como sumários. Quanto ao tipo de operação, foram realizadas nove aquisições de participação e uma aquisição de carteira que, como destacado na Figura 9, envolveram 32 empresas. 
Figura 8 - Rede de empresas que realizaram operações, 2016

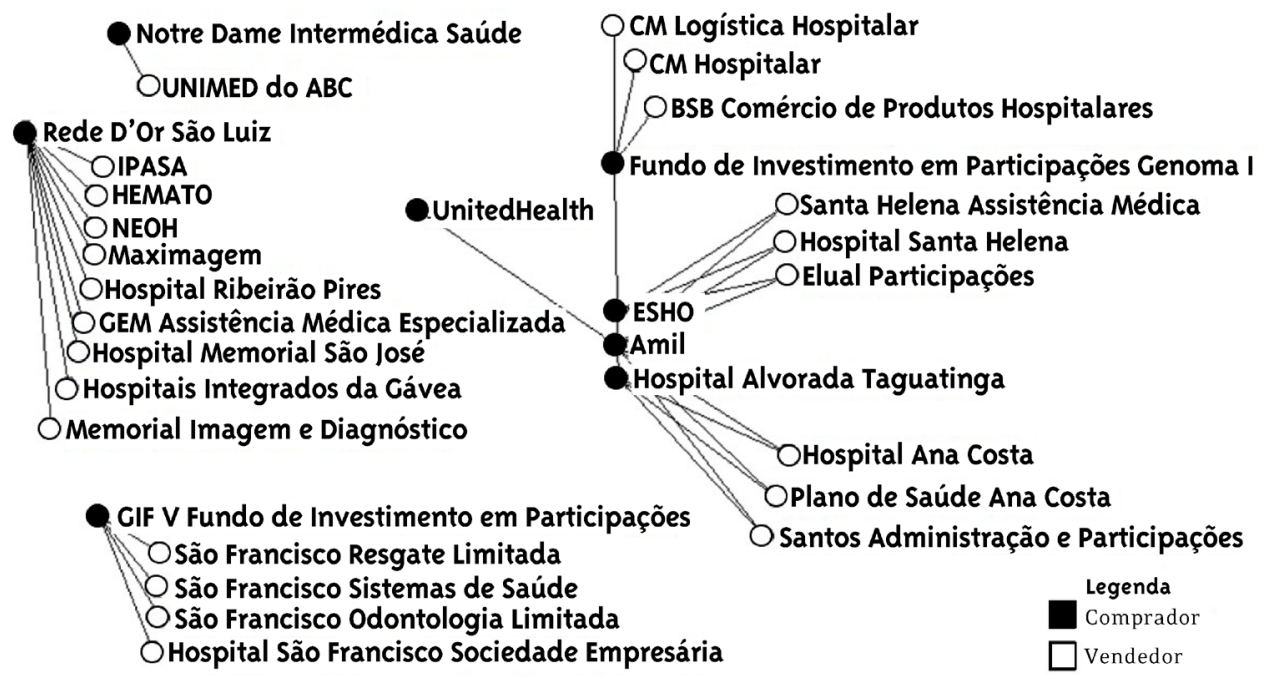

Figura 9-Rede de empresas que realizaram operações, 2017

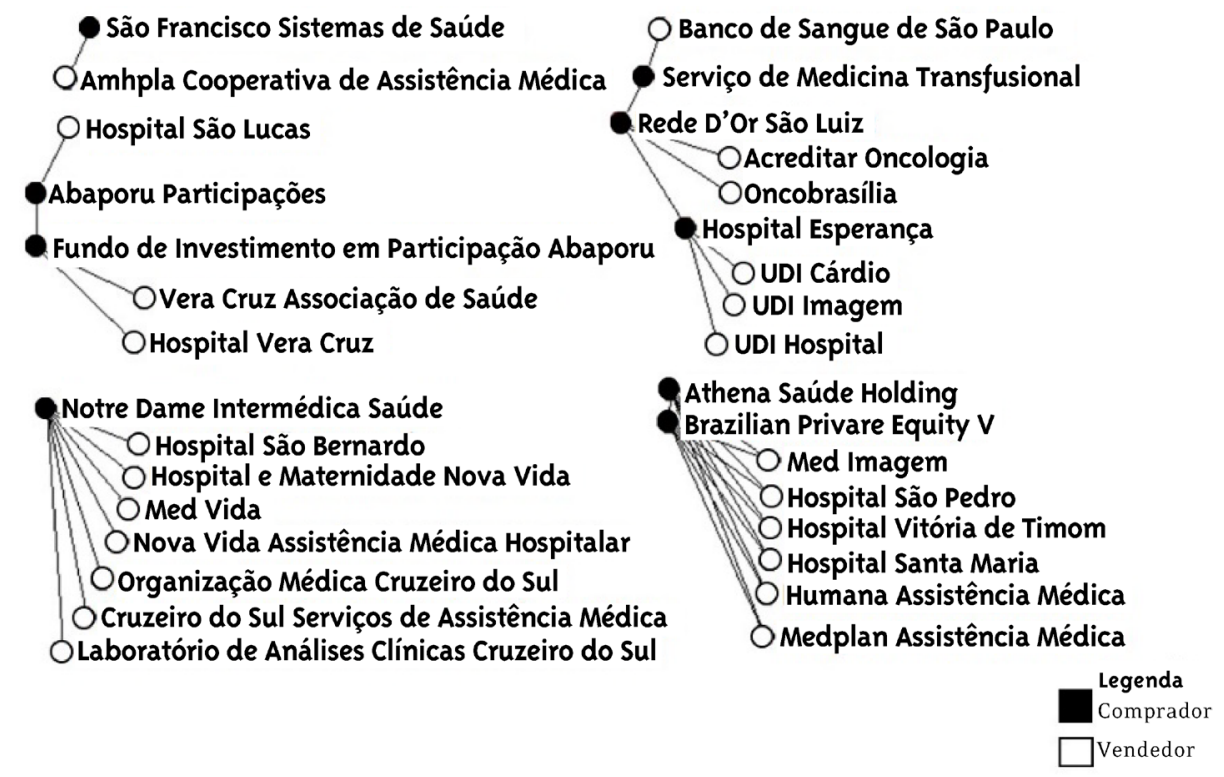

Em 2017 se destacaram a Rede D’Or São Luiz e a Notre Dame Intermédica Saúde, que participaram de três operações cada. AAbaporu Participações e o Fundo de Investimento em Participação Abaporu, ambos do grupo Cyrela, participaram de duas operações.

Durante o período pesquisado (2009 a 2017) foram realizados 93 atos de concentração econômica que envolveram 211 empresas e três pessoas físicas. Na Figura 10 observa-se que, durante o período pesquisado, três grupos se consolidaram no mercado de hospitais e planos de saúde no Brasil, sendo a Rede D’Or São Luiz, a Amil Assistência Médica Internacional e a Qualicorp.

Além de se verificarem operações horizontais de hospitais e planos de saúde, também foram identificadas operações verticais entre hospitais e/ou planos de saúde com empresas de outros serviços da área da saúde. Além disso, houve operações de conglomerado, aquelas realizadas com mercados não relacionados (Angeli; Maarse, 2012; Ross; Westerfield; Jordan, 2016). 


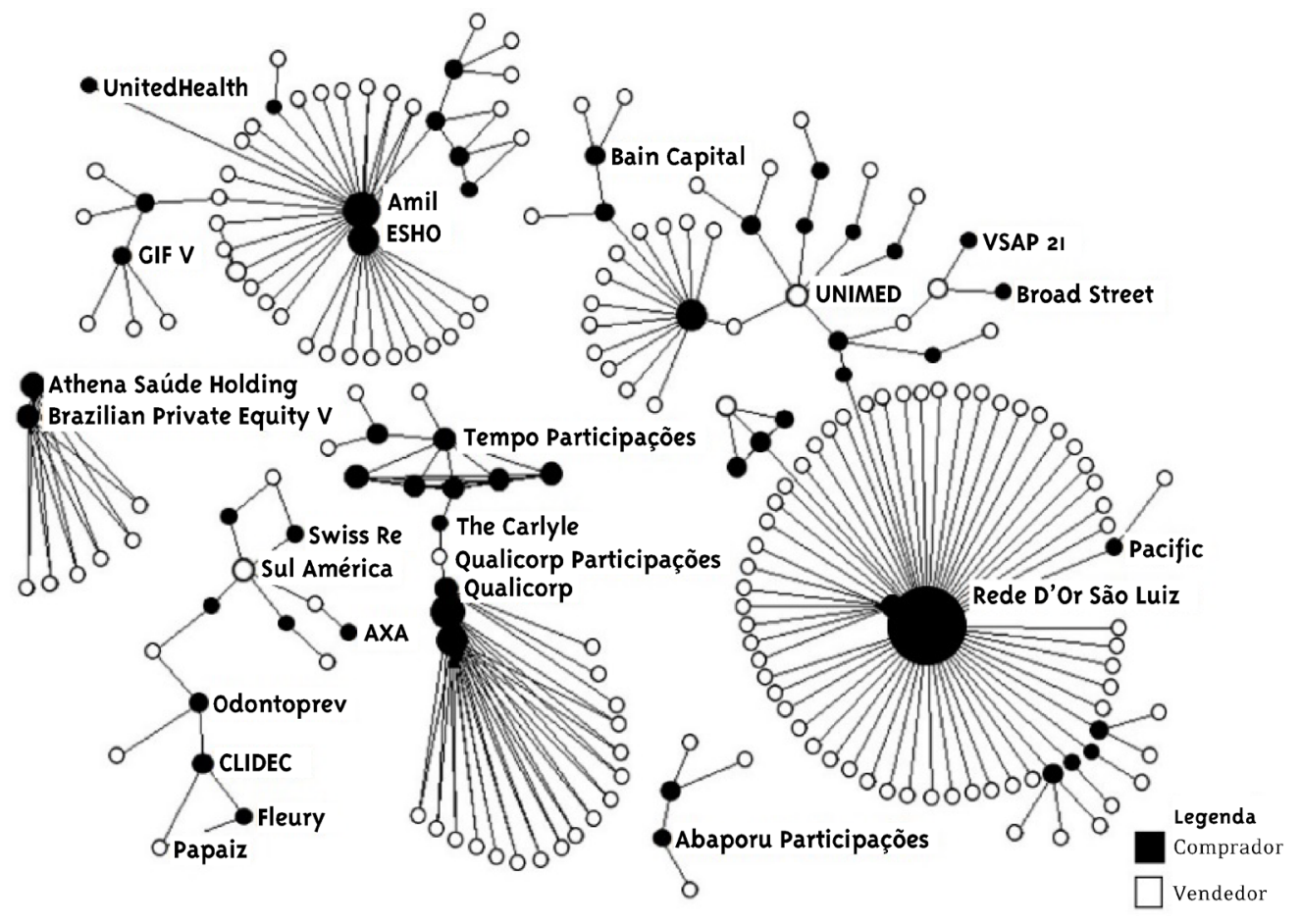

Analisando-se a distância média entre os atores, verifica-se que, em média, um ator está a 6,23 atores de outro ator na rede. Isso significa que a distância entre qualquer ator na rede é de 6,23 atores e, quanto menor esse valor, mais próximos são os atores de uma rede. A Densidade da Rede foi de o,o11, ou seja, existem 1,1\% de relações do número de relações possíveis na rede, ou, ainda, de todas as ligações possíveis na rede, existem 1,1\% de ligações. Quanto maior esse resultado, mais densa é uma rede.

O grau de centralidade consiste no número de atores com os quais um ator está diretamente ligado, demonstrando a influência e o poder de um ator sobre outros (Ghiradini, 2015). As 10 empresas com maior grau de centralidade estabeleceram ligações com 36\% das empresas da rede. A Rede D’Or São Luiz apresentou o maior grau de centralidade (54), ou seja, ela tem influência direta sobre $13 \%$ dos atores da rede. Na Tabela 2 estão listadas as 10 empresas que registraram maior grau de centralidade na rede que foi formada a partir dos atos de concentração de 2009 a 2017, que envolveram hospitais e planos de saúde.

Tabela 2 - Grau de Centralidade

\begin{tabular}{lcc} 
Empresa & $\begin{array}{l}\text { Grau de } \\
\text { Centralidade }\end{array}$ & $\%$ \\
Rede D’ Or São Luiz & 54 & $13 \%$ \\
$\begin{array}{l}\text { Amil Assistência Médica } \\
\text { Internacional }\end{array}$ & 20 & $5 \%$ \\
Qualicorp & 16 & $4 \%$ \\
$\begin{array}{l}\text { ESHO - Empresa de Serviços } \\
\text { Hospitalares }\end{array}$ & 14 & $3 \%$ \\
Notre Dame Intermédica Saúde & 14 & $3 \%$ \\
Tempo Participações & 8 & $2 \%$ \\
Oncotech Oncologia & 7 & $2 \%$ \\
Athena Saúde Holding & 7 & $2 \%$ \\
Brazilian Private Equity V & 7 & $2 \%$ \\
Rede UNIMED & 6 & $1 \%$ \\
\hline
\end{tabular}

O grau de intermediação considera a importância de cada ator nas ligações que são estabelecidas na rede; é a distância entre os atores, a possibilidade que um ator tem de intermediar as comunicações entre os pares (Ghiradini, 2015). As 10 empresas com maior grau de intermediação estão listadas na Tabela 3. 
Tabela 3 - Grau de Intermediação entre os Autores

$\begin{array}{lcc}\text { Empresa } & \begin{array}{c}\text { Grau de } \\ \text { Intermediação }\end{array} & \% \\ \text { Rede D’ Or São Luiz S.A } & 4.929 .000 & 22 \% \\ \text { UNIMED - Rio Participações } & 2.744 .000 & 12 \% \\ \text { Hospital Norte D'Or de } & 2.590 .000 & 11 \% \\ \text { Cascadura } & 2.489 .000 & 11 \% \\ \text { Rede UNIMED } & 1.656 .000 & 7 \% \\ \text { Notre Dame Intermédica Saúde } & 1.602 .000 & 7 \% \\ \text { UNIMED do ABC } & 876.000 & 4 \% \\ \begin{array}{l}\text { Amil Assistência Médica } \\ \text { Internacional }\end{array} & 621.000 & 3 \% \\ \text { Oncotech Oncologia } & 415.000 & 2 \% \\ \text { Intermédica Sistema de Saúde } & 320.00 & 1 \% \\ \text { ESHO - Empresa de Serviços } & & \\ \text { Hospitalares } & & \end{array}$

A Rede D’Or São Luiz apresentou maior grau de intermediação, com $22 \%$, sendo seguida pela Unimed - Rio Participações, com 12\%; o Hospital Norte D'Or de Cascadura e a Rede Unimed, com $11 \%$.
Dessa forma, essas empresas se caracterizaram como atores "ponte" entre as empresas.

A Rede D’Or São Luiz apresenta o maior grau de intermediação por estar diretamente e/ou indiretamente ligada a várias empresas da rede, uma vez que participou de atos de concentração de forma direta, com 54 empresas, e participou de forma indireta de seis operações, por meio das empresas de seu grupo. Como exemplo, em 2017 o Hospital Esperança (pertencente à Rede D'Or) adquiriu participação em três empresas do Grupo UDI, sendo UDI Cárdio, UDI Imagem e UDI Hospital.

O Hospital Norte D'Or de Cascadura ficou em segundo lugar, com 12\% de intermediação, por ser o ator “ponte” entre a Rede D’Or São Luiz e a Rede Unimed. O Hospital Norte D’Or de Cascadura (pertencente à Rede D’Or) adquiriu participação na Unimed - Rio Participações, em 2011.

Analisando a participação do capital estrangeiro, com base na Figura 11, observa-se que os principais grupos da rede têm investimento estrangeiro e que praticamente toda a rede apresenta influência direta ou indireta de capital estrangeiro.

\section{Figura II - Rede de empresas que realizaram operações - capital estrangeiro, 2009 a 2017}

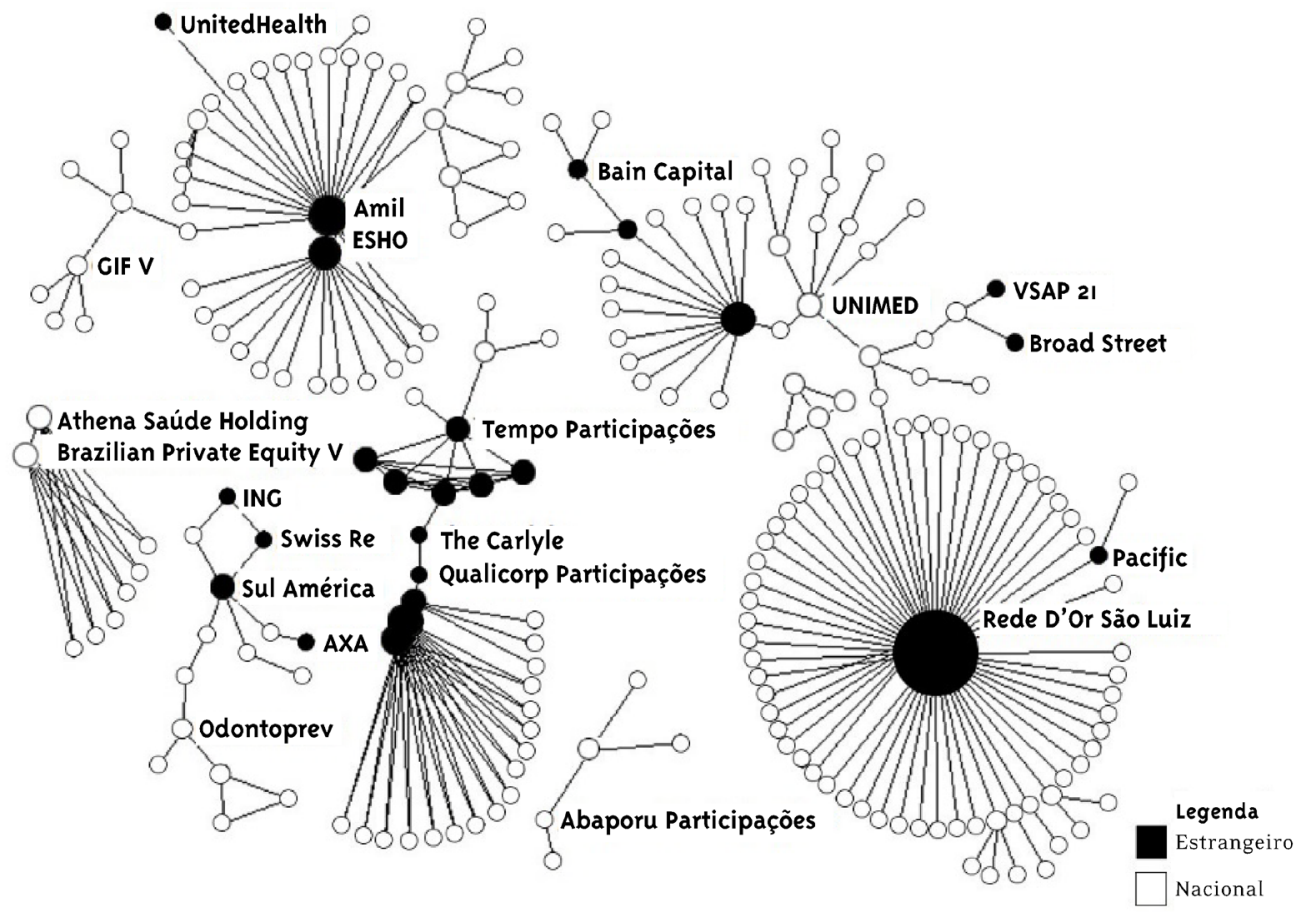


A Pacific RDSL Participações, de Singapura, gerida pelo grupo GIC Ventures, foi um dos principais atores internacionais, pois, em 2015, adquiriu participação no maior grupo da rede, a Rede D’Or São Luiz. A The Carlyle Group também se destaca, pois adquiriu outros dois grupos de destaque na rede, o Qualicorp, em 2010 e o Tempo Participações, em 2015. Embora não tenha sido analisada pelo Cade, foi possível identificar também a entrada do grupo UnitedHealth, por ter adquirido o controle da Amil Assistência Médica Internacional, em 2012.

Em linhas gerais, no que tange à participação do capital estrangeiro na área da saúde, os resultados são similares aos de Outreville (2007) e Angeli e Maarse (2012), uma vez que também foi possível identificar que predominam operações transfronteiriças realizadas por empresas dos Estados Unidos, país este que também lidera, em escala mundial, o número de operações de fusões e aquisições, de acordo com Unctad (2017).

Com base nos dados apresentados na Figura 11, pode-se verificar a formação de uma rede com 214 atores, agrupados em três grupos principais, Rede D’Or São Luiz, Amil Assistência Médica Internacional e Qualicorp. A Rede D’Or São Luiz apresentou o maior grau de centralidade e intermediação, ou seja, foi o ator com maior influência, poder e importância na rede, exercendo influência direta em $13 \%$ dos atores da rede.

As empresas que mais se movimentaram para a realização de atos de concentração no mercado de hospitais e planos de saúde foram a Rede D’Or São Luiz, a Amil Assistência Médica Internacional e a Qualicorp, todas com participação de investidores estrangeiros.

Verificou-se que estes grupos concentraram os investimentos nas regiões mais populosas do país, com maior renda e com maior cobertura de planos de saúde. Por meio da análise de rede, percebe-se que estas empresas ampliaram e diversificaram sua atuação no mercado, o que pode aumentar sua influência e, especificamente, seu poder, este último destacado, inclusive, pelo próprio Cade (2018).

Essa forte presença de investidores estrangeiros na saúde pode representar riscos e benefícios. Como benefícios, podem-se destacar as considerações de Smith (2004), que apresenta o investimento estrangeiro como uma fonte livre de custo, o que pode representar recursos adicionais, desde que regulados, para a melhoria da qualidade e da eficiência dos serviços, liberando recursos públicos para outros segmentos da saúde, muito embora essa melhoria esteja condicionada a um incremento da capacidade produtiva atual.

Em termos de riscos, o referido autor salienta o fato de as grandes corporações, com melhor fluxo financeiro, criarem um deslocamento de profissionais da saúde do setor público para o setor privado, tornando-se um sistema ainda mais polarizado, que alocará mais recursos aos ricos em detrimento das classes pobres e, até mesmo, forçar a realocação de gastos públicos vultosos para equiparar desigualdades do setor público em decorrência da forte presença de capitais privados (Smith, 2004).

Em concordância, Scheffer (2015) salienta que o aumento de investimentos estrangeiros e a valorização do setor privado de saúde promovem uma concorrência desleal com o setor público, abrindo espaço para a formação de um sistema "segmentado, incapaz de assegurar o acesso a todos os níveis de atenção, em todas as regiões, inclusive nos vazios sanitários e para populações vulneráveis e negligenciados" (Scheffer, 2015, p. 664), pois é onde o setor privado não tem interesse, por oferecer menor retorno financeiro.

Nesse sentido, as considerações de Outreville (2007) também coadunam no fato de a capacidade desse tipo de investimento fortalecer ou enfraquecer o sistema de saúde, sendo propenso a contribuir fortemente para a segmentação do mercado, concentrando-o nos segmentos de maior renda.

Isto posto, dadas as alterações na política pública da saúde, no que tange à permissibilidade de investimentos estrangeiros, tanto na saúde suplementar quanto no mercado da saúde como um todo, é urgente que sejam estabelecidas políticas para analisar esses riscos e benefícios ao país.

\section{Considerações finais}

O objetivo geral, neste trabalho, foi caracterizar a dinâmica das redes de operações de atos de concentração econômica em hospitais e planos de saúde no Brasil. Foram identificados 93 atos de concentração econômica que envolveram hospitais e/ou planos de saúde, no período entre os anos de 2009 e 2017. 
Desses 93 atos de concentração, constatou-se a participação de 211 empresas e três pessoas físicas nos atos de concentração econômica. Verificouse que nove empresas participaram de $66 \%$ das operações realizadas, sendo a Rede D’Or São Luiz, em uma análise individualizada, responsável por $22 \%$ dessas operações, e que passou a ser controlada pelo grupo estrangeiro GIC Ventures, de Singapura. Constatou-se que a maioria das operações realizadas foi aprovada pelo Cade sem restrições, fator que pode ser favorável para aumentar a concentração econômica no setor da saúde.

Quanto à dinâmica de redes, a partir da base de dados, verificou-se uma rede com três grandes grupos, em que a Rede D’Or São Luiz, a Amil Assistência Médica Internacional e a Qualicorp, que são controladas por grupos estrangeiros, apresentam o maior Grau de Centralidade, ou seja, são as empresas que têm o maior número de ligações na rede.

Neste sentido, é possível compreender os reflexos da abertura do mercado da saúde brasileiro a investidores estrangeiros, a predominância de operações de aquisições de empresas por estes grupos e a latente necessidade de que sejam estabelecidas políticas para analisar os riscos e os benefícios dessa nova realidade para o mercado da saúde brasileiro, para que eventuais reflexos no sistema de saúde sejam previamente contingenciados. Embora os desdobramentos dessas operações na saúde do brasileiro ainda não tenham sido mensurados pela comunidade científica, os apontamentos de Filippon (2015) e Hiratuka, Rocha e Sarti (2016) evidenciam a importância de discussões acerca dessa política econômica adotada e os desafios que ela representa.

Nesta pesquisa, a análise limitou-se ao mapeamento dos atos de concentração na área da saúde, especificamente planos de saúde e hospitais, dos anos de 2009 a 2017, com análise da versão pública dos processos disponibilizados na base do Cade, não tendo sido analisados os contratos celebrados entre as partes interessadas. Também como limitação, cita-se a não verificação do valor das operações, por ser uma informação confidencial, na maioria dos processos disponibilizados pelo Cade.

$\mathrm{Na}$ oportunidade, salienta-se que pesquisas futuras podem ser conduzidas com a proposta de verificar impactos nessa organização industrial, sua estrutura, conduta e desempenho, bem como reflexos nos preços e na qualidade dos serviços ofertados por empresas objeto de ato de concentração econômica.

\section{Referências}

ÁLVARES, A.; AGUILAR, N. Manual introdutório à análise de redes sociais: medidas de centralidade. 2005. Disponível em: <http://www2.unicentro.br/ lmqqa/files/2016/o5/Manualintrodutorio_ex_ ucinet.pdf >. Acesso em: 22 jan. 2018.

ANDRADE, M. V. et al. Estrutura de concorrência no setor de operadoras de planos de saúde no Brasil. Brasília, DF: Opas, 2015.

ANGELI, F.; MAARSE, H. Mergers and acquisitions in Western European health care: Exploring the role of financial services organizations. Health Policy. Amsterdam, v. 105, n. 2, p. 265-272, 2012. BRASIL. [Constituição (1988)]. Constituição da República Federativa do Brasil de 1988. Brasília, DF: Presidência da República, 2016 [1988]. Disponível em: <https://www.planalto. gov.br/ccivil_03/constituicao/constituicao.htm>. Acesso em: 6 jun. 2018.

BRASIL. Lei no 9.656, de 3 de junho de 1998. Dispõe sobre os planos e seguros privados de assistência à saúde. Diário Oficial da União: Brasília, DF, 3 jun. 1998. Disponível em: <http://www.planalto.gov.br/ ccivil_o3/Leis/L9656.htm>. Acesso em: 6 jun. 2018.

BRASIL. Lei n ${ }^{0}$ 13.097, de 19 de janeiro de 2015. Reduz a zero as alíquotas da Contribuição para o PIS/PASEP [...]; e dá outras providências. Diário Oficial da União: Brasília, DF, 19 jan. 2015. Disponível em: <https://www.planalto.gov.br/ ccivil_03/_ato2015-2018/2015/lei/l13097.htm>. Acesso em: 18 jun. 2018.

BRASIL. Lei no 8.08o, de 19 de setembro de 1990. Dispõe sobre as condições para a promoção [...] e dá outras providências. Diário Oficial da União, Brasília, DF, 19 set. 199o. Disponível em: <http:// www.planalto.gov.br/ccivil_o3/LEIS/L8o8o.htm>. Acesso em: 6 jun. 2018.

BRASIL. Medida Provisória no $1.908-18$, de 24 de setembro de 1999. Altera a Lei no 9.656, de 3 de junho de 1998 [...], e dá outras providências. 
Diário Oficial da União, Brasília, DF, 4 set. 1999. Disponível em: <http://www.planalto.gov.br/ ccivil_o3/mpv/Antigas/19o8-18.htm>. Acesso em: 6 jun. 2018.

BRASIL. Medida Provisória n ${ }^{0}$. 2177-44, de 24 de agosto de 2001. Altera a Lei no 9.656 [...] e dá outras providências. Diário Oficial da União, Brasília, DF, 24 ago. 2001. Disponível em: <http://www.planalto. gov.br/ccivil_o3/mpv/2177-44.htm>. Acesso em: 6 jun. 2018.

BRASIL. Senado Federal. Comissão Mista da MPV 656/2014. Parecer técnico $n^{\circ} 44$, de 2014-CN. Brasília, DF, 2014. Disponível em: <http://www. camara.gov.br/proposicoesWeb/prop_mostrari ntegra? codteor $=1293518 \&$ filename $=$ Tramitacao$\mathrm{PAR}+44+\mathrm{MPV} 65614+\% 3 \mathrm{D} \% 3 \mathrm{E}+\mathrm{MPV}+656 / 2014>$. Acesso em: 6 jun. 2018.

CADE - CONSELHO ADMINISTRATIVO DE DEFESA ECONÔMICA. Cadernos do Cade: Atos de concentração nos mercados de planos de saúde, hospitais e medicina diagnóstica. Brasília, DF: Departamento de Estudos Econômicos, 2018. Disponível em: <http://www.cade.gov.br/ acesso-a-informacao/publicacoes-institucionais/ publicacoes-dee/cadernos-do-cade-atos-deconcentracao-nos-mercados-de-planos-de-saudehospitais-e-medicina-diagnostica.pdf $>$. Acesso em: 26 set. 2018.

CADE - CONSELHO ADMINISTRATIVO DE DEFESA ECONÔMICA. Guia para análise de atos de concentração horizontal. Brasília: Departamento de Estudos Econômicos, 2016. Disponível em: <https://cdn.cade. gov.br/Portal/centrais-de-conteudo/ publicacoes/guias-do-cade/guia-paraanalise-de-atos-de-concentracao-horizontal. pdf?_ga=2.6482610.1685238981.1610628269285367626.1598541266>. Acesso em: 14 jan. 2021. CADE - CONSELHO ADMINISTRATIVO DE DEFESA ECONÔMICA. Resolução nº 2, de 29 de maio de 2012. Disciplina a notificação dos atos de que trata o artigo 88 da Lei no 12.529, de 30 de novembro de 2011, prevê procedimento sumário de análise de atos de concentração e dá outras providências. 2012. Disponível em: <http://www. cade.gov.br/assuntos/normas-e-legislacao/ resolucao/resolucao-2_2012-analise-atosconcentracao.pdf/view>. Acesso em: 30 set. 2017.

GHIRADINI, P. P. B. Regressão diferenças em diferenças: uma análise de fusões no setor hospitalar brasileiro. 2015. Dissertação de Mestrado (Mestrado em Economia) - Faculdade de Economia, Administração, Contabilidade e Ciência da Informação e Documentação, Universidade de Brasília, Brasília, DF, 2015.

HERMANN, M. G.; HERMANN, C. F. Who makes foreign policy decisions and how: an empirical inquiry. International Studies Quarterly, Oxford, v. 33, n. 4, p. 361-387, 1989.

HIRATUKA, C.; ROCHA, M. A. M.; SARTI, F. Mudanças recentes no setor privado de serviços de saúde no Brasil: internacionalização e financeirização. In: GADELHA, P.; NORONHA, J. C.; DAIN, S.; PEREIRA, T. R. (Org.). Brasil saúde amanhã: população, economia e gestão. Rio de Janeiro: Fiocruz, 2016.

HITT, M. A.; IRELAND, R. D.; HARRISON, J. S. Mergers \& acquisitions: a guide to creating value for stakeholders. Oxford: Oxford University Press, 2001.

MENEZES, J. P. C. B. Fusões e aquisições, concorrência e concentração: investimento estrangeiro em saúde suplementar no Brasil. Tese (Doutorado em Administração) - Faculdade de Ciências Econômicas, Universidade Federal de Minas Gerais, Belo Horizonte, 2019.

OUTREVILLE, J. F. Foreign direct investment in the health care sector and most-favoured locations in developing countries. The European Journal of Health Economics, New York, v. 8, n. 4, p. 305-12, 2007.

PGF - PROCURADORIA GERAL FEDERAL. Informação $n^{\circ}$. oo2/20o8/PROGE/GECOS. Rio de Janeiro, 2008. Disponível em: <http://www.agu.gov. $\mathrm{br} /$ page/download/index/id/1550906>. Acesso em: 18 jun. 2018.

ROSS, S. A.; WESTERFIELD, R.; JORDAN, B. D. Fundamentals of corporate finance. McGraw-Hill Education, 2016. 
SCHEFFER, M. O capital estrangeiro e a privatização do sistema de saúde brasileiro. Cadernos de Saúde Pública, Rio de Janeiro, v. 31, p. 663-666, 2015.

SMITH, R. D. Foreign direct investment and trade in health services: a review of the literature. Social Science \& Medicine, Amsterdam, v. 59, n. 11, p. 2313-2323, 2004 .

UNCTAD. Annex table 11. Number of cross-border M\&As by region/economy of seller, 199o-2016. In:
World Investment Report 2017: Investment and the Digital Economy. Geneva: United Nations Publication, 2017. Disponível em: <https://unctad. org/search?keys=Number + of + cross-border $+M \% 26$ As+by+region\%2Feconomy+of+seller $>$. Acesso em: 15 jan. 2018.

ZOCRATTO, K. B. F. Mercado da saúde: uma análise da oferta e demanda. Revista da $A M D E$, Belo Horizonte, v. 12, n. 1, p. 154-164, 2014.

\section{Contribuição dos autores}

Oliveira e Menezes contribuíram de forma substancial para a concepção ou design da pesquisa e para a aquisição, análise e interpretação dos dados. Todos os autores elaboraram o trabalho, fizeram a revisão crítica do manuscrito quanto ao conteúdo intelectual $e$ aprovaram a versão final a ser publicada.

Recebido: $11 / 6 / 2020$

Reapresentado: $21 / 1 / 2021$

Aprovado: 24/2/2021 
Apêndice I-Relação dos atos de concentração econômica em hospitais e/ou planos de saúde de 2009 a 2017

\begin{tabular}{|c|c|c|c|}
\hline Processo & Ano & Interessados & $\begin{array}{l}\text { Segmento(s) do(s) } \\
\text { principal(ais) interessado(s) }\end{array}$ \\
\hline $08012.007443 / 2009-41$ & 2009 & $\begin{array}{l}\text { I-São Francisco Saúde Sociedade Empresária LTDA } \\
\text { 2-Amico Saúde LTDA }\end{array}$ & Plano de Saúde \\
\hline $08012.009906 / 2009-17$ & 2009 & $\begin{array}{l}\text { 1-Amil Assistência Médica Internacional LTDA } \\
\text { 2- Medial Participações S.A } \\
\text { 3-Medial Saúde S.A }\end{array}$ & Plano de Saúde \\
\hline $08012.002248 / 2009-24$ & 2009 & $\begin{array}{l}\text { 1- Intermédica Sistema de Saúde S.A } \\
\text { 2-Medicamp Assistência Médica LTDA }\end{array}$ & Hospital e Plano de Saúde \\
\hline $08012.008325 / 2009-50$ & 2009 & $\begin{array}{l}\text { ı-Tempo Participações S.A } \\
\text { 2- Unibanco Saúde Seguradora S.A }\end{array}$ & Plano de Saúde \\
\hline 08012.008989/2009-19 & 2009 & $\begin{array}{l}\text { 1-Bradesco Dental S.A } \\
2 \text {-Odontoprev S.A }\end{array}$ & Plano de Saúde \\
\hline $08012.003389 / 2010-06$ & 2010 & $\begin{array}{l}\text { I- AMIL Assistência Médica Internacional LTDA } \\
\text { 2-ASL Assistência a Saúde LTDA. } \\
\text { 3-CEAME Centro Especializado de Atendimento } \\
\text { Médico LTDA. }\end{array}$ & Plano de Saúde \\
\hline $08012.004902 / 2010-78$ & 2010 & $\begin{array}{l}\text { 1-ESHO - Empresa de Serviços Hospitalares LTDA } \\
\text { 2-Hospital Pró-Cardíaco S.A }\end{array}$ & Hospital \\
\hline $08012.006190 / 2010-21$ & 2010 & $\begin{array}{l}\text { 1-Sul América Seguro Saúde S.A } \\
2 \text { - BB Seguros Participações S.A }\end{array}$ & Plano de Saúde \\
\hline $08012.010274 / 2010-60$ & 2010 & $\begin{array}{l}\text { I-FMG Empreendimentos Hospitalares S.A } \\
\text { 2-São Luiz Operadora Hospitalar S.A }\end{array}$ & Hospital \\
\hline $08012.000917 / 2010-67$ & 2010 & $\begin{array}{l}\text { I- UNIMED Porto Alegre Sociedade Cooperativa de } \\
\text { Trabalho Médico LTDA. } \\
\text { 2- UNIMED Centro Sul, Sociedade Cooperativa de } \\
\text { Trabalho Médico LTDA. }\end{array}$ & Plano de Saúde \\
\hline $08012.004756 / 2010-81$ & 2010 & $\begin{array}{l}\text { 1-FMG Empreendimentos Hospitalares S.A } \\
\text { 2-Hospital e Maternidade Brasil S.A }\end{array}$ & Hospital \\
\hline 08012.010675/2010-10 & 2010 & $\begin{array}{l}\text { I-FMG Empreendimentos Hospitalares S.A } \\
\text { 2-Hospital e Maternidade Assunção S.A } \\
\text { 3- Assunção Imagem S.A } \\
\text { 4- Ressonância Assunção S.A. }\end{array}$ & Hospital \\
\hline $08012.010734 / 2010-50$ & 2010 & $\begin{array}{l}\text { I-Amil Assistência Médica Internacional LTDA } \\
\text { 2-Excelsior Med LTDA }\end{array}$ & Plano de Saúde \\
\hline $08012.011280 / 2010-34$ & 2010 & $\begin{array}{l}\text { I-FMG Empreendimentos Hospitalares S.A } \\
\text { 2-Casa de Saúde e Maternidade Rio de Janeiro S.A } \\
\text { 3-Casa de Saúde e Maternidade Joari S.A } \\
\text { 4-JMJB Diagnósticos e Serviços Hospitalares S.A } \\
\text { 5- LE Participações Societárias S.A } \\
\text { 6- Medise Medicina Diagnóstico e Serviços S.A } \\
\text { 7- Hospital Realcordis S.A }\end{array}$ & Hospital \\
\hline
\end{tabular}

continua... 


\section{Apêndice I - Continuação}

Processo

Ano

Interessados

Segmento(s) do(s)

principal(ais) interessado(s)

$08012.012150 / 2010-19$

$08012.013181 / 2010-97$

$08012.013200 / 2010-85$

$08012.008112 / 2010-61$

$08012.000596 / 2011-81$

$08012.002872 / 2011-46$

$08012.004596 / 2011-51$

$08012.006525 / 2011-92$

$08012.006542 / 2011-20$

$08012.009232 / 2011-67$

$08012.009582 / 2011-23$

$08012.011059 / 2011-67$

$08012.011421 / 2011-08$

$08012.011602 / 2011-26$

$08012.004653 / 2011-00$
2010

2010

2010

2010

2011

2011

I - Medgrupo Participações S/A

2- Hospital Renascer Ltda

I - Hospital e Maternidade São Luiz S.A

20112 - Oncotech Oncologia Ltda

3-Cotefil Hospital Geral Ltda

I- Centro de Tratamento em Oncologia S.A

2011

2011

2011

2011

2011

2-Vivaile Serviços de Saúde Ltda

1- Oncotech Oncologia Ltda

2 - Centro Radioterápico da Gávea Ltda.

3 - Serviços de Radioterapia São Peregrino Ltda.

2011

4 - CORAL - Centro de Oncologia e Radioterapia Ltda

5 - LFC Serviços Médicos Ltda

6-Scanmed - Aluguel de Máquinas e Equipamentos Ltda

I-Rede D'Or

2011

2-MAIS - Multi Assistência Incorporada à Saúde Ltda

3 - Centro Hospitalar São Marcos S.A

I-Qualicorp Administradora de Benefícios S.A.

2-Qualicorp Corretora de Seguros S.A.

3-Divicom Administradora de Benefícios Ltda.

4-Divicom Gestão de Benefícios Ltda.

5 - Divicom Corretora de Seguros S.S

6-Divicom Assessoria e Negócios S.S.
Hospital

Plano de Saúde

Hospital

Plano de Saúde

Hospital e Plano de Saúde

Hospital

Hospital

Hospital

Plano de Saúde

Plano de Saúde

Hospital

Hospital

Hospital

Hospital

Plano de Saúde 


\section{Apêndice I - Continuação}

\section{Processo}

$08012.002189 / 2012-90$

$08012.005776 / 2012-31$

$08012.002520 / 2012-71$

$08012.002680 / 2012-11$

$08012.002866 / 2012-70$

$08012.005540 / 2012-02$

$08012.006134 / 2012-59$

08700.004065/2012-91

$08012.005539 / 2012-70$
$08012.009575 / 2011-21$

$08012.000309 / 2012-14$

1 - Qualicorp Administradora de Benefícios S.A

2-Qualicorp Corretora de Seguros S.A

2011 3-Adplan Administração e Planejamento de

Benefícios Ltda

4 - Destak Corretora de Seguros Ltda

I- Central Médica de Prevenção LTDA

2012 2-UNIMED Porto Alegre Sociedade Cooperativa de

Trabalho Médico LTDA

I- Pio Sodalicio das Damas de Caridade de Caxias do Sul

2- UNIMED Nordeste RS Sociedade Cooperativa de

Serviços Médicos LTDA

1-Qualicorp Administradora de Benefícios S.A

2-Qualicorp Corretora de Seguros S.A.

2012

3-Afinidade Administradora de Benefícios Ltda

4 - Equilibrar Corretora de Seguros Ltda

I- Rede D'Or São Luiz S.A

2 - Sinisgalli Administração e Participações S.A

3-Hospital e Maternidade Nossa Senhora de Lourdes S.A

4 - Instituto de Especialidades Pediátricas de São

Paulo S.A

Plano de Saúde

Plano de Saúde

Plano de Saúde

Plano de Saúde

Hospital

5- Angiodinâmica S.A

6- Lithocenter S.A

7 - Centro Diagnóstico NSL S.A

I-Carpevie - Centro de Medicina Integrada Ltda

2- LAF - Empresa de Serviços Hospitalares Ltda

3-Mariliz Lima - Ginecologia e Obstetrícia e Erickson

Élun - Cirurgia do Aparelho Digestivo Ltda

1 - Carpevie - Centro de Medicina Integrada Ltda

20122 - EGB ol Empreendimentos e Participações Ltda

3-ADIX Empreendimentos Imobiliários Ltda

I- Rede D'Or São Luiz S.A

2-Hospital Santa Luzia S.A

3-Hospital do Coração do Brasil S.A.

I- Jorge Nevai Moli Filho

2012

2 - Pedro Junqueira Molı

3 - Paulo Junqueira Moll

Plano de Saúde

4 - Santa Luzia Assistência Médica S.A

I-ESHO - Empresa de Serviços Hospitalares S.A

2- Sociedade Civil Clinvac LTDA

Hospital

1 - Qualicorp Administradora de Benefícios S.A

2-Qualicorp Corretora de Seguros S.A

3-Aliança Administradora de Benefícios de Saúde Ltda

Plano de Saúde 


\section{Apêndice I - Continuação}

Processo Pro

$08700.004150 / 2012-59$

$08700.004151 / 2012-01$

$08012.003324 / 2012-14$

$08700.005472 / 2012-15$

$08700.008474 / 2012-66$

$08700.010284 / 2013-90$

$08700.005729 / 2013-10$

$08700.006494 / 2013-83$

$08700.008540 / 2013-89$

$08700.003059 / 2013-05$

$08700.005730 / 2013-44$

$08700.006171 / 2013-90$

$08700.007610 / 2013-81$

$08700.009118 / 2013-40$

$08700.010530 / 2013-03$
I-Rede D'Or São Luiz S.A

2012 2-Medgrupo Participações S.A

3-Hospital Santa Lúcia S.A

2012

I-Rede D'Or São Luiz S.A

2-Acreditar Oncologia Ltda

Hospital

1 - Qualicorp Administradora de Benefícios S.A

2-Qualicorp Corretora de Seguros S.A

3-PS - Padrão Administradora de Benefícios Ltda

2012

4 - Padrão Administração e Corretagem de Seguros Ltda

Plano de Saúde

5-PS Brasil Administração e Corretagem de Seguros Ltda

6 - Voloto Consultoria Empresarial Ltda

I - VSAP 21 Fundo de Investimento em Participações

2-Oncoclínicas do Brasil Serviços Médicos S.A

I-CLIDEC - Clínica Dentária Especializada Cura D'ars Ltda

2 - Fleury Centro de Procedimentos Médicos S.A

3-Papaiz Associados Diagnósticos por Imagem S/S Ltda

I- Swiss Re Direct Investments Company Ltd

$2013 \quad 2-$ ING Insurance International B.V

3-Sul América S.A

I- Unimed Odonto S.A

2- Unimed Vitória Cooperativa de Trabalho Médico

1- Unimed-Rio Cooperativa de Trabalho Médico do Rio

2013 de Janeiro Ltd

2-Golden Cross Assistência Internacional de Saúde Ltda

I-Amil Assistência Médica Internacional S.A

20132 - Seísa Serviços Integrados de Saúde Ltda

3-Hospital Carlos Chagas S.A

I - Sulasapar Participações S.A

2- ING Insurance Tntemational B.V

Plano de Saúde

I- Unimed Odonto S.A

2- Unimed Recife Cooperativa de Trabalho Médico

1-Odontoprev S.A

2- BB Seguros Participações S.A

I- Rede D'Or São Luiz S.A

2013

2-Hospital Norte D'Or de Cascadura S.A

I - UNIMED - Rio Participações e Investimentos S.A

2-Oncoclínica - Centro de Tratamento Oncológico Ltda

1- Unimed Seguros Saúde S.A

2-Tempo Saúde Seguradora S.A
Plano de Saúde

Plano de Saúde

Hospital

Hospital e Plano de Saúde

Hospital

Hospital

Plano de Saúde

Plano de Saúde

Plano de Saúde

Plano de Saúde

Hospital e Plano de Saúde

Plano de Saúde 


\section{Apêndice I - Continuação}

Processo

$08700.002568 / 2014^{-93}$

$08700.004443 / 2014-06$

$08700.010625 / 2014^{-08}$

$08700.011555 / 2014-05$

$08700.003676 / 2015-64$

$08700.001601 / 2015-49$

$08700.002317 / 2015-90$

$08700.003123 / 2015-10$

$08700.003337 / 2015-88$

$08700.005963 / 2015^{-17}$

$08700.008189 / 2015-98$
Hospital

I-Rede D'Or São Luiz S.A

2 - Brospar Participações Ltda

3-Proncordis - Pronto Atendimento Cardiológico Ltda

4 - Rede Lav Lavanderia Industrial Hospitalar Ltda

I- Caixa Seguros Holding S.A

2- Tempo Participações S.A

2014 3-Odonto Empresas Convênios Dentários Ltda

4 - Prevdonto Odonto Empresa Assistência

Odontológica Ltda

1-Bain Capital Brazil Participações Ltda

2-Intermédica Sistema de Saúde S.A

3-Interodonto - Sistema de Saúde Odontólogica Ltda

4 - Notre Dame Seguradora S.A

1-Qualicorp S.A

2-Connectmed CRC Cons, Adm e Tecnologia em

2014

Saúde Ltda

3-Gama Saúde Ltda

I-Rede D'Or São Luiz S.A

2- Hospital Vilia-Lobos Ltda

Hospital

I- Rede D'Or São Luiz S.A

2014 2-Associação Hospitalar Sino Brasileiro

3-Tomo-Med Centro de Diagnóstico e Tratamento Ltda

Hospital

I- ESHO - Empresa de serviços hospitalares S.A

2-COl-Clínicas Oncológicas S.A

Plano de Saúde

1 - Rede D'Or São Luiz S.A

2- Hospital e Maternidade Bartira Ltda

Hospital

I- Broad Street Principal Investments, L.L.C

2 - Oncoclínicas do Brasil Serviços Médicos S.A

Hospital

I- BTC Pactual Saúde Fundo de Investimento

2015 em Participações

Hospital

2-Rede D'Or São Luiz S.A

I- Rede D'Or São Luiz S.A

2- Oncologia Rede D'Or S.A

Hospital

I- AXA Corporate Solutions Brasil e América Latina

2015 Resseguros, S.A

Plano de Saúde

2-SulAmérica Companhia Nacional de Seguros

I- Notre Dame Intermédica Saúde S.A

2- Santamália Saúde S.A

3- Hospital Bosque da Saúde S.A

4-Hospital Montemagno S.A

Hospital e Plano de Saúde

5 - Acqua Blue Transporte de Água LTDA

6- Acqua Magma Lavanderia LTDA 


\section{Apêndice I - Continuação}

Processo

$08700.010373 / 2015-06$

$08700.011192 / 2015-99$

$08700.012624 / 2015-89$

$08700.011951 / 2015^{-13}$

$08700.008541 / 2015-95$

$08700.005620 / 2016-25$

$08700.000266 / 2016-42$

08700.000430/2016-11
Hospital e Plano de Saúde

Hospital

Hospital e Plano de Saúde

Plano de Saúde

Hospital

Plano de Saúde

Hospital e Plano de Saúde

Hospital

4-Memorial Imagem e Diagnóstico Ltda

5-Maximagem - Diagnóstico por Imagem Ltda

6- HEMATO - Serviços de Hemoterapia Ltda

7-IPASA - Investimento Participação e Administração S.A.

I - Fundo de Investimento em Participações Genoma I

2-CM Hospitalar S.A

2016
Hospital

4- BSB Comércio de Produtos Hospitalares S.A 


\section{Apêndice I - Continuação}

Processo

\section{Processo}

08700.006574/2016-8

$08700.007004 / 2016-17$

$08700.007555 / 2016-72$

08700.007556/2016-17

$08700.008061 / 2016-13$

$08700.005455 / 2017-92$

$08700.004084 / 2017-21$

$08700.001221 / 2017-76$

$08700.005859 / 2017-86$

$08700.002013 / 2017-94$

$08700.008007 / 2017-41$

I-Amil Assistência Médica Internacional S.A

2-ESHO - Empresa de Serviços Hospitalares S.A

20163 -Santa Helena Assistência Médica S.A.

4- Hospital Santa Helena S.A

5-Elual Participações S.A

2016

I- Notre Dame Intermédica Saúde S.A

2- UNIMED do ABC - Cooperativa de Trabalho Médico

I- Rede D'Or São Luiz S.A

2- Hospital Ribeirão Pires Ltda

I- Rede D'Or São Luiz S.A

2-GEM Assistência Médica Especializada Ltda

I- Rede D'Or São Luiz S.A.

2- Hospitais Integrados da Gávea S.A

I-Amil Assistência Médica Internacional S.A

2- Hospital Alvorada Taguatinga Ltda

20163 -Santos Administração e Participações S.A

4- Plano de Saúde Ana Costa Ltda

5- Hospital Ana Costa Ltda

I- Notre Dame Intermédica Saúde S.A

2-Organização Médica Cruzeiro do Sul S.A

3-Cruzeiro do Sul Serviços de Assistência Médica S.A

4 - Laboratório de Análises Clínicas Cruzeiro do Sul LTDA

I- Rede D'Or São Luiz S.A

2 - Acreditar Oncologia S.A.

3-Oncobrasília - Instituto Brasiliense de Oncologia Clínica Ltda

I- Notre Dame Intermédica Saúde S.A

2-Hospital São Bernardo S.A

I- Serviço de Medicina Transfusional SMTS Ltda

2017 2-Banco de Sangue de São Paulo e Serviços de

Hemoterapia Ltda

I-São Francisco Sistemas de Saúde Sociedade

2017 Empresária Ltda

2-Amhpla Cooperativa de Assistência Médica

I- Hospital Esperança S.A.

2-UDI Hospital - Empreendimentos Médico-

Hospitalares do Maranhão Ltda

2017
3-UDI Cárdio - Unidade de Diagnóstico e Tratamento

Cardiológico Ltda

4-UDI Imagem - Unidade de Diagnóstico por

Imagem Ltda
Hospital e Plano de Saúde

Plano de Saúde

Hospital

Hospital

Hospital

Hospital e Plano de Saúde

Hospital e Plano de Saúde

Hospital

Hospital e Plano de Saúde

Hospital

Plano de Saúde

Hospital 


\section{Apêndice I - Continuação}

\begin{tabular}{|c|c|c|c|}
\hline Processo & Ano & Interessados & $\begin{array}{l}\text { Segmento(s) do(s) } \\
\text { principal(ais) interessado(s) }\end{array}$ \\
\hline $08700.004255 / 2017-12$ & 2017 & $\begin{array}{l}\text { I-Abaporu Participações S.A } \\
2 \text { - Hospital São Lucas S.A }\end{array}$ & Hospital \\
\hline $08700.003803 / 2017-97$ & 2017 & $\begin{array}{l}\text { I- Athena Saúde Holding S.A } \\
\text { 2- Brazilian Private Equity V - Fundo de Investimento } \\
\text { em Participação } \\
\text { 3- Med Imagem S/C } \\
\text { 4- Hospital São Pedro S/C } \\
\text { 5- Hospital Vitória de Timon S/C } \\
\text { 6- Hospital Santa Maria Ltda } \\
\text { 7- Humana Assistência Médica Ltda } \\
\text { 8- Medplan Assistência Médica Ltda }\end{array}$ & Hospital e Plano de Saúde \\
\hline $08700.002450 / 2017-16$ & 2017 & $\begin{array}{l}\text { 1- Notre Dame Intermédica Saúde S.A } \\
\text { 2- Hospital e Maternidade Nova Vida Ltda } \\
\text { 3- Med Vida Assistência Médica Hospitalar Ltda } \\
\text { 4- Nova Vida Assistência Médica Hospitalar Ltda }\end{array}$ & Hospital e Plano de Saúde \\
\hline $08700.002164 / 2017-42$ & 2017 & $\begin{array}{l}\text { I- Fundo de Investimento em Participação Abaporu } \\
\text { 2- Hospital Vera Cruz S.A } \\
\text { 3-Vera Cruz Associação de Saúde }\end{array}$ & Hospital e Plano de Saúde \\
\hline
\end{tabular}

